Responsabilidade Pré-Negocial...

\title{
RESPONSABILIDADE PRÉ-NEGOCIAL E CULPA IN CONTRAHENDO NO DIREITO ADMINISTRATIVO BRASILEIRO
}

1. Pode-se dizer, sem incidir em simplificações mutiladoras, que a questão do dever de indenizar decorrente da celebração de contrato inválido por ação ou omissão culposa de uma das partes tem sua origem no século passado, como célebre estudo de Jhering, publicado em $1861^{1}$. O tema, entretanto, acabou por ganhar uma outra dimensão, abrangendo hoje todo o campo designado, genericamente, por responsabilidade pré- negocial ${ }^{2}$. Em muitos países, a resposta dos problemas que se inserem nessa área tem sido dada pela doutrina e peta jurisprudência, à margem de quaisquer textos legislativos. É o que sucede, por exemplo, no direito alemão ${ }^{3}$ e, também, no direito privado brasileiro ${ }^{4}$. Em alguns outros, a legislação civil mais moderna contém regras específicas sobre a responsabilidade pré- negocial, com fundamento na boa fé. São exemplos disso o Código Civil grego, de 1940 (art. 197 e 198)5 , o Código Civil

1 Culpa in contrahendo oder Schadenersatz bei nichtigen oder nicht zur Perfektion gelangten Verträgen. In Jahrbücher fur die Dogmatik des heutigen römischem und deutschen Privatrecht, vol. IV, p. 331 e segs.

2 Ver, sobre essa evolução, Mário Júlio de Almeida Costa. Responsabilidade Civil Pela Ruptura das Negociações Preparatórias de um Contrato, Coimbra. 1984. Coimbra Edit. Ltda., p. 33 e segs., e, mais recentemente. Antônio Menezes Codeiro. Tratado de Direito Civil Português. Coimbra, 1999. Almedina, vol. I. p. 331 e segs.

3 Ver Karl Larenz. Lehrbuch des Schuldrechts. München. 1984. C. H. Beck, $1^{\circ}$ vol. p.106 e segs.

4 A bibliografia brasileira sobre a matéria está indicada por Almeida Costa, op. cit., p.41. nota 27

5 Art. 197: "No curso das negociações para a conclusão de um contrato, as partes se devem, multuamente, a conduta ditada pela boa fé e os usos nas relações de negócio". Art. 198: "aquele que causou por culpa sua prejuízo à outra parte, no curso das negociações para a conclusão de um contrato, é obrigado a repará-lo, mesmo se o contrato não se concluiu. A disposição relativa à prescrição da reclamação nascida de atos ilícitos aplica-se por analogia à prescrição desta reclamação". 
Responsabilidade Pré-Negocial...

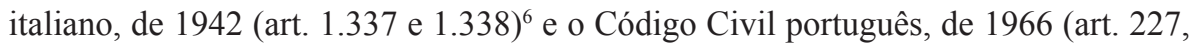
$\left.\mathrm{n}^{0} 1\right)^{7}$. O projeto de Código Civil brasileiro, já aprovado pelo Senador Federal e que, agora, tramita na Câmara dos Deputados, ocupa-se da matéria no art. 421.

$\mathrm{Na}$ esteira do ensaio de Jhering, cujas linhas principais, em muitos aspectos, são ainda hoje dominantes no direito alemão, a parte a que se imputava a invalidade do contrato deveria indenizar a outra, pelos danos por esta sofridos. Sendo nulo ou inexistente o contrato seria incoerente falar-se em responsabilidade contratual. Fundarse-ia, então, em ato ilícito? Tal indenização, entretanto, estaria restrita ao interesse negativo, ou seja, deveria recompor-se para o prejudicado apenas o status quo ante, como se as negociações e o contrato nulo nunca tivessem existido ${ }^{8}$.

Ora, nem sempre a invalidade de um contrato decorre de culpa de uma das partes, e o mesmo se poderá dizer da ruptura das tratativas ou negociações preparatórias. Se toda a frustração de um contrato, ou por sua invalidade, ou por sua não consumação em virtude do desinteresse de quem mantinha tratativas, caracterizasse ato ilícito, restaria seriamente abalado o princípio da liberdade de contratar. Fossem por essas ou por outras razões, o que não cabe aqui examinar, o certo é que, a pouco e pouco, a questão da responsabilidade pré-negocial começou a afastar-se da responsabilidade aquiliana para aproximar-se de uma responsabilidade muito semelhante à que existe para as partes ligadas por contrato, em decorrência da boa fé.

Os deveres derivados da boa fé manifestam-se não apenas depois de já concluído o contrato, quando assumem a condição de deveres anexos (neben Pflichte), mas já antes, nos preparatórios "contatos negociais" (geschãftlichen Kontakts) ${ }^{9}$, e fracionam-se em deveres de distinta índole, como, por exemplo, os de segurança e de lealdade, abrangendo este último os de esclarecimento, informação e discrição. No que tange ao descumprimento dos deveres de lealdade, a indenização relaciona-se com os chamados danos da confiança (Vertrauenschaden). Estes consistem, principalmente, nas despesas feitas pela parte que teve suas expectativas frustradas com o rompimento das negociações ou com a invalidade do contrato ${ }^{10}$. Indeniza-se, portanto, o interesse negativo e não o interesse positivo, ou seja, o Interesse no cumprimento do contrato (Erfüllungsinteresse), solução que, no direito alemão, também é aplicada aos casos de invalidade do contrato por impossibilidade material ou jurídica da prestação, quando a impossibilidade era conhecida ou devia ser conhecida pela outra parte ${ }^{11}$. Contudo, a

6 Art. 1.337: "Le parti, nello svolgimento delle traltative e nella formazione dei contrato, devono comportasi secondo buona fede". Art. 1.338: "La parte que, conoscendo o dovendo conoscere la esistenza di una causa d'invalidità dei contralto, non ha datto notizia all'altra parte e tenuta a risarcire il danno da questa risentito per avere confidato, senza sua colpa, nella validità dei contratto".

7 Art. 227, $n^{\circ}$ 1: "Quem negocia com outrem para a conclusão de um contrato deve, tanto nos preliminares como formação dele, proceder segundo as regras da boa fé, sob pena de responder pelos danos que culposamente causar à outra parte" .

8 Menezes Cordeiro, op. cit., p. 331.

9 Larenz, op. cit., p. 106.

10 Larenz, op. cit., p. 112.

11 BGB, § 307. Ver Palandt. Bürgerliches Geselzbuch, 54º ed. München 1995. C. H. Beck, p. 383 e segs., critico com relação àsolução dada. 
Responsabilidade Pré-Negocial...

jurisprudência alemã mais recente vem já admitindo, notadamente no direito comercial, a indenização pelo interesse positivo ou no cumprimento do contrato, quando, por exemplo, o procedimento culposo de uma das partes impediu que o contrato se realizasse ${ }^{12}$.

2. É este, em síntese muito apertada, o status quaestionis, quer nos países que acolheram expressamente na sua legislação civil a responsabilidade pré-contratual, quer em outros que, mesmo sem esse reconhecimento legislativo, acabaram por aceitar, em maior ou menor medida, direta ou indiretamente, as sugestões da doutrina e da jurisprudência germânicas, aliás amplamente difundidas, incorporando aquela modalidade de responsabilidade ao seu direito, pela via da doutrina e da jurisprudência.

3. No direito brasileiro, o Decreto-Lei ${ }^{\circ} 2.300$, de 21.11.86, que dispunha sobre licitações e contratos da Administração Federal, enunciava, no parágrafo único do seu art. 49, a regra de que a invalidação do contrato pela autoridade estatal não exonerava a Administração "do dever de indenizar o contratado, pelo que este houver executado, até a data em que ela (a nulidade) for declarada, contanto que não lhe seja imputável, promovendo-se a responsabilidade de quem lhe deu causa”. E, no $\S 1^{\circ}$ do art. 39, prescrevia que "a anulação do procedimento licitatório, por motivo de ilegalidade, não gera obrigação de indenizar, ressalvado o disposto no parágrafo único do art. 49".Por outro lado, o caput do art. 49 estabelecia que "a declaração de nulidade do contrato administrativo opera retroativamente, impedindo os efeitos jurídicos que ele, ordinariamente, deveria produzir, além de desconstituir os já produzidos”.

Reafirmava-se, com essas normas, uma tradição que vem do direito romano segundo a qual os atos jurídicos nulos não produzem efeito. Desse modo, quem executou contrato nulo tem, por certo, direito a ser indenizado pelo que executou, não com base, obviamente, no contrato, mas sim com fundamento na noção de enriquecimento injustificado ou sem causa, simetricamente ao que sucede com o funcionário de fato, que não recebe; vencimentos, mas sim mera indenização pelo trabalho que prestou.

Quanto à extensão dessa indenização, mesmo antes do Decreto-Lei n. 2.300/ 86, a jurisprudência brasileira já deixava perceber, embora o número de decisões não seja muito expressivo, que deveriam ser ressarcidos, apenas, as despesas e gastos efetivamente feitos, e não os lucros que a parte teria com a execução do contrato ${ }^{13}$.

12 Palandt. op. cit., p. 343; Larenz op. cit. , p. 113, que observa, todavia, que em se tratando de vício de forma, que uma parte conhecia e silenciou, a indenização será apenas pelo interesse negativo, pois, do contrario, se esvaziaria a exigência. Refere, porém, que a jurisprudência, em muitos desses casos, ainda que não reconheça pretensão ao adimplemento tem autorizado a indenização pelo descumprimento do contrato, não se restringindo, portanto ao interesse negativo (cf. nota 28).

13 Nesse sentido, o antigo Tribunal Federal de Recursos, ao julgar embargos infringentes na apelação cível n. 37.253, do Rio de Janeiro, relator o Min. Aldir Passarinho: "Cumpre distinguir duas situações diversas: uma é o problema da validade do contrato administrativo, outra é o da remuneração dos serviços efetivamente prestados. em decorrência desse contrato, embora nulo. A nulidade do contrato não impede a remuneração destes serviços. nem permite que o Estado ou a Administração Pública se locuplete à custa de quem realmente prestou serviços. privando-o da correspondente remuneração. A proibição do enriquecimento ilícito, princípio geral de direito, atua no campo do Direito Administrativo, ainda com maior intensidade, porque, se a cada um particular não é lícito se locupletar à custa alheia, com muito maior razão o Estado não poderá fazê-lo. Desde que auferiu vantagens a Administração Pública, e beneficiou-se com os serviços, nada sendo alegado em relação aos mesmos, sua efetividade e qualidade, terá que pagar o seu custo, sob pena de ocorrer o mencionado locupletamento indevido, à custa de quem os prestou, apenas porque o contrato firmado é nulo. Contrato nulo, segundo o 
Responsabilidade Pré-Negocial...

A doutrina também se inclinava para esse mesmo rumo ${ }^{14}$.

A Lei n. 8.666, de 21 de junho de 1993, que, com as alterações introduzidas pelas Leis n. 8.883/94 e n. 9.032/95, constitui o diploma vigente no que diz com as licitações e contratos da Administração Pública da União, dos Estados, do Distrito Federal e dos Municípios, reproduziu, com algumas modificações, as regras do Decreto-Lei n. 2.300/86.

$\mathrm{O} \S 1^{\circ}$ do art. 49 repete a norma de que "a anulação do procedimento licitário por motivo de ilegalidade não gera obrigação de indenizar”, mas expressamente ressalva o disposto no parágrafo único do art. 59. Para facilitar a compreensão, cabe reproduzir, aqui, essa regra jurídica na sua integralidade:

"Art. 59: A declaração de nulidade do contrato administrativo opera retroativamente. impedindo os efeitos jurídicos que ele, ordinariamente deveria produzir, além de desconstituir os já produzidos.

Parágrafo único: A nulidade não exonera a Administração do dever de indenizar o contratado pelo que este houver executado até a data em que ela for declarada e por outros prejuízos regularmente comprovados, contanto que não lhe seja imputável, promovendo-se a responsabilidade de quem lhe deu causa".

A novidade com relação ao texto do Decreto-Lei n. 2.300/86 está no acréscimo da expressão “...e por outros prejuízos regularmente comprovados", que agrega à indenização com fundamento no enriquecimento injustificado uma outra modalidade de ressarcimento, já agora por quaisquer outros prejuízos, desde que observadas duas condições: os danos deverão ser devidamente comprovados, e a invalidade não poderá ser imputada ao contratante.

O fundamento dessa segunda espécie de responsabilidade está precisamente no que se chamou a "descoberta jurídica" 15 de Jhering, a culpa in contrahendo, após

conhecido princípio, não produz efeito, mas não está em cobrança, no caso, a remuneração no contrato convencionada. $\mathrm{O}$ fundamento da ação proposta não é o contrato nulo, mas o fato da prestação de serviços, em proveito da Administração que não é gratuita e deverá ser remunerada". Nesse caso, porém, como constou da ementa do acórdão, entendeu o Tribunal que "a indenização deve fazer-se pelo justo e exato valor do custo dos serviços, sem inclusão de qualquer lucro". Posta nesses termos a decisão cria uma situação de perplexidade, pois é muito difícil discernir entre custo e lucro e um serviço, o que não ocorre, por exemplo, com uma obra. Qual o custo de um serviço de advogado e qual o lucro? Como o prestador do serviço poderia provar que estava cobrando apenas o custo e não o lucro? Neste particular, no contexto da época, bem mais razoável e acertada se nos afigura a solução dada pelo Tribunal de Justiça de São Paulo: Reconhecida a nulidade do contrato, certo é que a quem contratou irregularmente, com a Administração Pública não toca o direito de reclamar os esperados lucros, ou cláusula penal, ou perdas, e danos pelo inadimplemento, verbas que, somente se válido, o contrato, seriam de pretender. Tem o contratante, porém, o direito de obter remuneração pelos serviços prestados para que não haja injusto enriquecimento da Administração. Tal remuneração deverá atender aos preços normais dos serviços. Não apenas o reembolso do custo, porque se assim não fosse ainda ocorreria injusto locupletameto com obtenção de serviço por preço inferior ao normal." (RDA 54/119). Vejam-se, ainda, no concernente à indenização por enriquecimento injustificado, TJSP, RDA 99/278 e TJRS. RTJRS 27/228 e 28/147.

14 Na $2^{\circ}$ edição do seu Direito Administrativo Brasileiro (São Paulo. 1966. RT, p- 229) escrevia Hely Lopes Meirelles: "A inexistência de ajuste escrito ou o defeito de forma vicia irremediavelmente a manifestação de vontade da Administração e invalida o conteúdo contratual. Poderá em tal caso, ocorrer a obrigação de indenizar obras e serviços realizados sem contrato ou com contrato defeituoso, mas já então a causa do pagamento não é o contrato ilegal. mas sim a prestação de um fato ressarcível ao particular, estranho à falta interna da Administração".

15 Hans Dölle, Juristische Entdeckungen, in Deutscher Juristentag, 42 (1959), p. 1 e segs. 
Responsabilidade Pré-Negocial...

incorporada, como se viu, à noção de responsabilidade pré-contratual ou de responsabilidade pré-negocial, cujos horizontes são bem mais dilatados. Assim, antes, portanto, de a legislação civil brasileira ter tratado da responsabilidade pré-negocial (o que até agora não ocorreu), dela cuidou pela primeira vez entre nós, no campo normativo, a Lei n. 8.666/93, que enfeixa regras de direito público.

No direito europeu, pelo menos naqueles países que não consagraram formalmente, em texto legislativo, a responsabilidade pré-negocial, muito se discutiu a respeito das bases jurídicas dessa espécie de responsabilidade. Teria ela origem negocial? Resultaria da lei? $\mathrm{Ou}$, como afinal tem sido geralmente aceito, estaria intimamente ligada ao princípio da boa fé, que permeia e anima o ordenamento jurídico? ${ }^{16}$

Respondendo a essas indagações e referindo-se ao $\mathrm{n}^{\circ} 1$ do art. 227 do Código Civil português, assim se manifesta o Prof. Mário Júlio de Almeida Costa, expressando a opinião atualmente dominante na doutrina: "É vantajosa a existência da referida norma. Contudo, ainda que faltasse, caberia derivar, a responsabilidade pré-contratual, em sua plena dimensão, de outros preceitos que mais não representam do que a concretização de um princípio fundamental subjacente ao ordenamento jurídico - ao da boa fé - e que se imporia por si, independentemente dessas aflorações, na valoração e interpretação de qualquer fenômeno na esfera do direito."17.

E realmente, hoje se tem como assente, em toda a parte, que a responsabilidade pré-contratual se reconduz ao princípio da boa fé, que cobre todo o direito, tanto privado quanto público ${ }^{18}$.

4. No Brasil, as disposições da legislação ordinária de direito administrativo, pertinentes a licitações e contratos da Administração Pública, e, mais especificamente, concernentes com a culpa in contrahendo e com a responsabilidade pré-negocial, hão de ser também entendidas e interpretadas dentro da moldura mais ampla da responsabilidade do Estado, por atos lícitos e ilícitos, fixada no $\S 6^{\circ}$. do art. 37 da Constituição da República, de $1988^{19}$.

Sob essa luz, parece desde logo que as regras contidas no art. 49 , parágrafos $1^{\circ}$ e $2^{\circ}$, da Lei no $8.666 / 93$ - que excluem a obrigação de indenizar na hipótese de invalidação do procedimento licitatório e do contrato, ressalvado, entretanto, o disposto no parágrafo único do art. 59 da mesma Lei - são incompatíveis com o preceito constitucional . Este, efetivamente, não estabelece nenhuma limitação à responsabilidade do Estado, nem autoriza que a legislação ordinária a estabeleça. É por todos sabido que quando a Constituição não dispõe exaustiva ou suficientemente sobre qualquer

16 Sobre as diferentes teorias, ver Menezes Cordeiro, op. cit., p. 334 e segs.

17 op. cit. p. 41

18 Sobre a aplicação do princípio da boa fé ao direito público, ver os nossos Responsabilidade do Estado e Problemas Jurídicos. Resultantes do Planejamento in RDP 73 (1985), p. 84-94: Problemas jurídicos do Planejamento in RDA 170 (1987), p. 1-17. Princípios da Administração Pública e da Segurança Jurídica no Estado de Direito Contemporâneo in RDP 84 ( 1987), p. 46-63, com remissões bibliográficas e ao direito comparado.

$19 \mathrm{CF}$. art. 37, § $6^{\circ}$ : "As pessoas jurídicas de direito público e as de direito privado prestadoras de serviços públicos responderão pelos danos que seus agentes, nessa qualidade causarem a terceiros, assegurado o direito de regresso nos casos de dolo ou culpa". 
Responsabilidade Pré-Negocial...

matéria, costuma usar a cláusula "na forma da lei", ou semelhante, pela qual permite que o legislador ordinário dela trate com maiores minúcias, inclusive estabelecendo condições ou restrições. Desse modo, a responsabilidade do Estado pelos danos causados por seus agentes, nessa qualidade, não pode ser excluída ou mesmo restringida por norma jurídica infra-constitucional, sob pena de lesão à regra hierarquicamente superior, incorrendo, assim, na censura de inconstitucionalidade.

Bem se vê, pois, que o legislador ordinário, em tema de responsabilidade do Estado, está sujeito a condicionamentos que para ele inexistem quando se cuida de situações relacionadas com a responsabilidade dos indivíduos, surgidas no âmbito do direito privado.

A admitir-se como corretas essas premissas, deverá também ser irrecusável a conseqüência de que a invalidação, por autoridade administrativa, de procedimento licitatório, em virtude de ilegalidade, dá origem ao dever de indenizar do Estado, em razão da fé pública e da presunção de legitimidade que têm os atos do Poder Público. Configura-se, nessa hipótese, o que os autores alemães designam como "proteção da confiança" (Vertrauenschutz).

Não seria aceitável, em tais circunstâncias, por contrário ao princípio geral da boa fé, que o particular que atendeu ao Edital de licitação e fez gastos com a elaboração da proposta, na qual freqüentemente se incluem projetos ou exames técnicos, que são geralmente dispendiosos, devesse arcar com os prejuízos. Cabe perguntar, entretanto, se em todos os casos a indenização ficaria sempre restrita ao interesse negativo. A resposta deverá ser afirmativa quando a ilegalidade do procedimento licitatório estiver ligada à ilegalidade do objeto do contrato que seria celebrado ou das prestações nele previstas. Tratando-se, entretanto, de vício formal no procedimento licitatório, que poderia ser perfeitamente evitado, de modo a permitir que o contrato se realizasse sem qualquer defeito, ainda que não se dê a indenização pelo interesse positivo, pois a contratação ainda dependeria, de o licitante vencer o certame, parece que seria, pelo menos, de indenizar a perda da oportunidade ou da chance, como admitida sobretudo pelo direito francês ${ }^{20}$, mas também pela nossa doutrina ${ }^{21}$, apesar da dificuldade na fixação do quantum, a ser ressarcido, que nessas hipóteses se apresenta. É de sinalar-se, porém, que, segundo nosso entendimento, a perda de oportunidade ou de chance não se vincula, tão-somente, a outras licitações de que o interessado poderia ter participado, mas, com maior razão, àquela mesma que foi invalidada.

5. Ainda nesta ordem de considerações, ao examinar-se a extensão da indenização autorizada na norma expressa no parágrafo único do art. 59 da Lei ${ }^{\circ}$

8.666/93, de certa forma voltamos ao que já antes dissemos a propósito do procedimento licitatório. Também aqui desde logo cabe registrar que a restrição à indenização, a qual ficaria limitada ao que o contratado houvesse realmente executado e

20 Quanto ao problema no Direito Administrativo francês, ver René Chapus, Droit Administratif Général, Paris, Montchrestien,1993, vol. I, p. 983 e segs.

21 Ver José de Aguiar Dias, Da Responsabilidade Civil, Rio, Forense, 1994, vol.11, p. 720-721 e notas 33 e 34. 
Responsabilidade Pré-Negocial...

"aos outros prejuízos regularmente comprovados", hostiliza, claramente, a regra do $\S$ $6^{\circ}$ do art. 37 da Constituição Federal. Em outras palavras, nos termos da lei, só o dano emergente seria indenizável, em parte com fundamento no princípio que veda o enriquecimento injustificado, pois o contratado é ressarcido pelo que houver executado até a data em que a nulidade for declarada, e, em parte, com base na culpa in contrahendo e no princípio da boa fé, uma vez que terá direito também ao ressarcimento de "outros prejuízos regularmente comprovados", ou seja, pelo interesse negativo.

Neste ponto é necessário fazer algumas distinções. Se a invalidade prender-se à ilegalidade - e é de acrescentar-se - ou à impossibilidade do objeto do contrato ou da prestação nele prevista, além do ressarcimento das obras e serviços efetivamente executados, terá ainda o contratado direito a ser indenizado por todas as despesas efetuadas em razão da licitação e do contrato, tais como projetos, exames, trabalhos técnicos, providências preparatórias, viagens etc., salvo, apenas, os lucros que deixou de ter pela inexecução do contrato. A impossibilidade, jurídica ou física, impediria, porém, em qualquer hipótese, que o contrato fosse adimplido. E é esta precisamente a explicação por que, neste caso, o contratado não faz jus à indenização pelo interesse positivo, mas meramente pelo interesse negativo.

Contudo, se a nulidade do procedimento licitatório, que contamina o contrato, ou do próprio contrato, for de outra natureza, de tal sorte que a Administração Pública, se fosse mais cautelosa, poderia tê-la evitado, pensamos que a indenização, suposta a boa fé do contratado, deverá atender ao interesse positivo ou ao interesse no cumprimento do contrato.

Não teria sentido, em tal circunstância, restringir o ressarcimento ao interesse negativo ou ao dano, emergente, ou ainda apenas ao que o contratado "houver executado" até a data em que for declarada a invalidade, como está expresso no parágrafo único do art. 59, sem estendê-lo aos lucros cessantes, pois a frustração das expectativas do contratado se deveu única e exclusivamente à culpa da Administração

Pública. Também seria incoerente indenizar a perda comprovada de outras oportunidades ou chances, que se incluem nos "outros prejuízos regularmente comprovados", quando a chance ou oportunidade por excelência, que o contratado perdeu, foi a de executar o contrato, cuja nulidade foi causada pela culpa in contrahendo do Estado.

6. Percebe-se, assim, que a aplicação do princípio da boa fé e da noção de culpa in contrahendo às relações pré-contratuais do Estado, interpretados dentro da moldura do $\S 6^{\circ}$ do art. 37 da Constituição Federal, alarga consideravelmente a responsabilidade das entidades da Administração Pública, fato que tem passado despercebido à maioria de nossos doutrinadores, mesmo dos que escreveram comentários à Lei no 8.666/9322. As limitações ou restrições estabelecidas nessa Lei

22 Deve-se registrar, entretanto, a posição de Marçal Justen Filho, que, a nosso ver, examina corretamente a questão, colocando-a em termos constitucionais (Comentários à Lei de Licitações e Contratos Administrativos, São Paulo, Dialética, 1998, p. 497 e segs.). 
Responsabilidade Pré-Negocial...

à responsabilidade do Estado, especialmente as do $\S 1^{\circ}$ do art. 49 e do parágrafo único do art. 59, são absolutamente inconciliáveis com a Constituição Federal, daí porque a indenização deverá ser, em princípio, a mais ampla possível, observadas, entretanto, as particularidades que tivemos a preocupação de apontar e que influem na extensão do ressarcimento. Por força desses fatores variáveis, será tão equivocado dizer que, nos casos de nulidade do contrato, por culpa da Administração, o contratado não terá jamais direito a ser indenizado pelo interesse positivo, como afirmar o oposto, que ele sempre fará jus à indenização pelo interesse positivo. Já ressaltamos que há hipóteses em que a indenização será apenas pelo interesse negativo e outras em que ela será a mais larga que se possa imaginar, incluindo, também, o ressarcimento pelo interesse positivo.

7. Caberá ainda acrescentar, em conclusão, que a responsabilidade pré-negocial do Estado, no Brasil, abrange também as hipóteses de revogação da licitação. Quanto a este ponto, o art. 49 da Lei n. 8.666/93 estatui que "a autoridade competente para a aprovação do procedimento somente poderá revogar a licitação por razões de interesse público decorrente de ato superveniente devidamente comprovado, pertinente e suficiente para justificar tal conduta". A Lei silencia quanto à indenização no caso de revogação. Deve ponderar-se, no entanto, que o direito à indenização infere-se dos princípios gerais que pautam, entre nós, a responsabilidade civil e a responsabilidade do Estado e que, atualmente, cercam de uma proteção maior quem sofre o prejuízo do que quem causa o dano. Conquanto a revogação de licitação só seja admissível em virtude de fato superveniente e seja, além do mais, ato perfeitamente lícito, tais circunstâncias não servem para ilidir a responsabilidade do Estado pelo prejuízo que causou a quem fez despesas para atender ao edital ou às outras formas de convite para participar de licitação, previstas na Lei ${ }^{\circ} 8.666 / 93$. Não se pode esquecer que, como reconhecido pela nossa doutrina e jurisprudência, a responsabilidade do Estado prevista no $\S 60$. do art. 37 da Constituição Federal é, em princípio, objetiva, e compreende tanto os atos ilícitos quanto os lícitos. No tocante a estes últimos, desde que o dano seja anormal e especial requisitos exigidos desde os juristas medievais ${ }^{23}$ - deve ser indenizado. De resto, a indenização pelos prejuízos causados em decorrência de revogação de licitação vincula-se, também, à proteção da confiança $\mathrm{e}$, pois, ao princípio da boa fé.

23 Ver, a propósito, J. J. Gomes Canotilho, O Problema da Responsabilidade do Estado por Atos Lícitos, Coimbra, Almedina, 1974, p. 30. São particularmente expressivas as seguintes opiniões, de Jason de Mayno e de Baldo. Afirma o primeiro deles: "Hoc non procedere quando dispositio fieret per viam statutis generalis. quo casu etiam quod tollatur privato i us dominii non tamen datur recompensatio" (Isto não procede quando a disposição for realizada pela via de estatuto geral, caso em que, ainda que seja retirado o direito privado de propriedade, não será admitida indenização). E o segundo: "Civitas potest fare statutum, per quod auferatur i us privatum faciendum legem universalem. Sed faciendum privatum contra unum, hoc no potest". (A cidade pode fazer estatuto, pelo qual seja retirado o direito privado mediante lei universal. Mas fazê-lo especificamente contra um, isto não pode). 